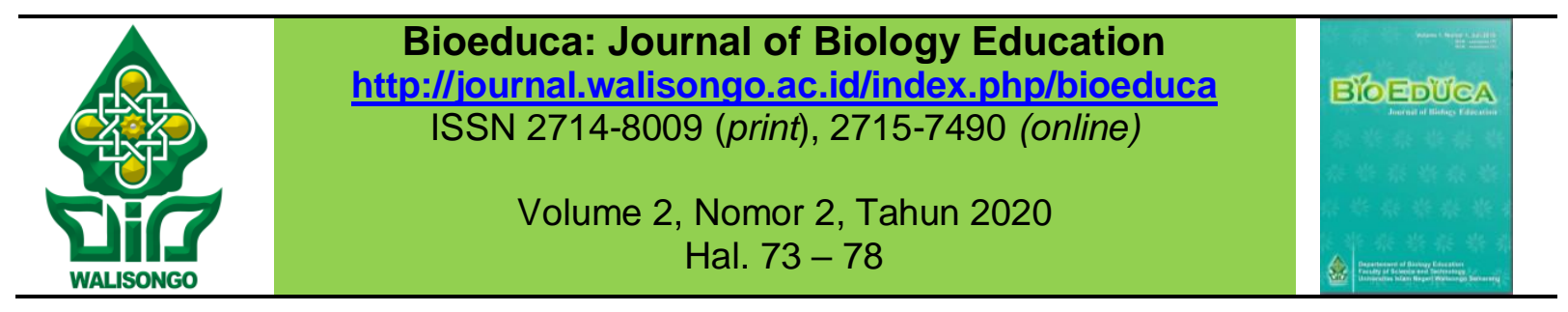

\title{
Efektivitas Bahan Ajar Berbasis Potensi Lokal Pada Materi Pisces Terhadap Hasil Belajar
}

\author{
Meyninda Destiara ${ }^{1^{*}}$ \\ ${ }^{1}$ Tadris Biologi, Universitas Islam Negeri Antasari Banjarmasin \\ *Email: meyninda.destiara@uin-antasari.ac.id
}

\begin{tabular}{|c|c|}
\hline Informasi Artikel & ABSTRAK \\
\hline $\begin{array}{l}\text { Submit: } 16-07-2020 \\
\text { Diterima: } 29-09-2020 \\
\text { Dipublikasikan: } 11-10-2020\end{array}$ & $\begin{array}{l}\text { Potensi lokal merupakan kekayaan suatu daerah yang dapat } \\
\text { dimanfaatkan sebagai bahan belajar mandiri bagi siswa. Salah } \\
\text { satu bentuk potensi lokal yang dapat dijadikan rujukan belajar } \\
\text { mandiri adalah jenis-jenis ikan pada materi pisces. Penelitian ini } \\
\text { bertujuan untuk melihat efektivitas bahan ajar berbasis potensi } \\
\text { lokal. Metode yang digunakan yaitu deskriptif-kuantitatif. } \\
\text { Berdasarkan hasil penelitian terlihat bahan ajar yang digunakan } \\
\text { efektif ketika digunakan dalam menunjang pembelajaran, dilihat } \\
\text { dari nilai n-gain rata-rata sebesar } 0,75 \text { dengan katagori tinggi. } \\
\text { Kata kunci: bahan aiar: efektivitas: potensi lokal. }\end{array}$ \\
\hline Penerbit & ABSTRACT \\
\hline $\begin{array}{l}\text { Program Studi Pendidikan } \\
\text { Biologi, Fakultas Sains dan } \\
\text { Teknologi, UIN Walisongo } \\
\text { Semarang }\end{array}$ & $\begin{array}{l}\text { Local potential is the wealth of an area that can be utilized as } \\
\text { material for independent learning for students. One form of local } \\
\text { potential that can be used as a reference for independent learning } \\
\text { is the types of fish in the Pisces material. This study aims to see } \\
\text { the effectiveness of teaching materials based on local potentials } \\
\text { that are developed. The method used is descriptive- quantitative. } \\
\text { Based on the research results, it can be seen that teaching } \\
\text { materials are used effectively when used in supporting learning, } \\
\text { seen from the average n-gain value of } 0,75 \text { with a high category. } \\
\text { Keywords: teaching material; effectiveness; local potential. }\end{array}$ \\
\hline
\end{tabular}

Copyright (O2020, Bioeduca: Journal of Biology Education

\section{PENDAHULUAN}

Potensi lokal merupakan kekayaan suatu daerah yang dapat dimanfaatkan sebagai bahan belajar mandiri bagi siswa (Destiara et al., 2018). Sesuai menurut (Prabowo et al., 2016) bahwa pengguna potensi lokal dalam pembelajaran dapat dikemas dalam bahan ajar berbasis Potensi lokal. Potensi lokal yang dimaksud yaitu berupa kekayaan keragaman jenis ikan yang terdapat di daerah Panjaratan.

Panjaratan merupakan daerah yang terdapat di Pelaihari, Kalimantan Selatan. Panjaratan memiliki sungai yang sangat panjang dan luas. Berdasarkan wawancara dengan penduduk sekitar sungai, bahwa di sungai tersebut memiliki berbagai jenis ikan. Namun sayangnya banyaknya jenis ikan tersebut belum pernah dimanfaatkan sebagai sarana belajar.

Biologi merupakan mata pelajaran yang berkaitan dengan lingkungan dan makhluk hidup (Utomo, 2016). Salah satu materi yang erat dikaitkan dengan potensi 
lokal adalah pada konsep vertebrata sub materi pisces. Pisces merupakan jenis vertebrata yang banyak habitatnya di air. Berdasarkan observasi pada materi ajar pisces pada buku belajar siswa kelas X SMA dan MA, disebutkan beberapa jenis ikan namun contoh spesies seperti Agnatha, Chondrichthyes dan Osteichthyes yang tampil pada buku tidak familiar. Oleh sebab itu perlu ada pengenalan jenis spesies yang lebih familiar yang sering dijumpai agar lebih mudah dipahami dan dimengerti, kemudian dikemas dalam sebuah bahan ajar.

Bahan ajar merupakan solusi untuk memperkaya materi yang berbasis potensi lokal (Nurhidayati \& Khaeruman, 2017). Bahan ajar merupakan media yang dapat menjadi fasilitator antara guru dan siswa untuk memahami materi lebih mendalam. Sesuai menurut Soegiranto (2010) memaparkan bahwa bahan ajar adalah bahan yang disusun oleh guru secara sistematis yang digunakan untuk peserta didik dalam pembelajaran. Dari pernyataan tersebut terkait bahan bahan ajar, maka seorang guru perlu memanfaatkan kekayaan potensi lokal sebagai bahan belajar. Oleh sebab itu perlu adanya pengembangan bahan ajar berbasis potensi lokal yang mengangkat jenis-jenis ikan agar menambah khanazah ilmu pada materi vertebrata di sekolah.

Sesuai dengan penelitian sebelumnya tentang efektivitas pemanfaatan bahan ajar berbasis potensi lokal yang dapat meningkatkan hasil belajar yaitu pada penelitian oleh (Mardotilah, 2016) dengan judul pembelajaran fisika menggunakan LKS berbasis kearifan lokal pada materi kalor dan perpindahannya, selanjutnya oleh (Anisa, 2017) dengan judul meningkatkan keterampilan berpikir kritris peserta didik melalui pembelajaran IPA berbasis Potensi Lokal Jepara. Sehingga dari kedua paparan penelitian tersebut menjadikan bahwa potensi lokal dapat membantu meningkatkan hasil belajar serta memiliki andil dalam memfasilitasi belajar dengan bantuan bahan ajar mandiri.

Berdasarkan pemaparan tentang potensi lokal sungai Panjaratan yang kaya akan berbagai jenis ikan, maka dapat menjadi landasan kriteria sebagai bahan ajar berbasis potensi lokal yang disusun berdasarkan jenis-jenis ikan terdapat di daerah tersebut. Sehingga potensi lokal desa Panjaratan dapat menjadi fasilitas belajar bagi siswa sekolah, khususnya siswa kelas X SMA/MA.

Setelah mengembangkan bahan ajar berbasis potensi lokal pada materi pisces. Bahan ajar kemudian dilakukan validasi untuk mengetahui kualitas bahan ajar tersebut, kemudian diuji cobakan efektivan bahan ajar dengan melakukan uji coba bahan ajar kepada siswa. Oleh sebab itu secara umum tujuan penentlian ini adalah untuk mengetahui keefektivan bahan ajar berbasis potensi lokal pada materi Pisces terhadap hasil belajar siswa.

\section{METODE PENELITIAN}

Penelitian ini merupakan penelitian pengembangan (Research and Development) atau disingkat $\mathrm{R} \& \mathrm{D}$, dengan mengunakan model pengembangan dari Borg and Gall yaitu 10 tahapan. 
Produk bahan ajar yang sudah dirancang, selanjutnya akan dilakukan validasi bahan ajar oleh para ahli. Tujuan validasi yaitu untuk mengetahui kualitas bahan ajar. Berdasarkan nilai kevalidtan, bahan ajar dibuat cukup valid (Destiara, dkk (2018).

Setelah mengetahui kualitas bahan ajar dari validasi pra ahli maka perlu dilanjutkan untuk mengetahui kelayakan bahan ajar dari uji coba keterbacaan

Uji coba keterbacaan dilakukan kepada 3 siswa kelas $X$ (sepuluh), setelah mengetahui kelayakan bahan ajar maka tahap selanutnya adalah mengetahui keefektivan bahan ajar dengan melakukan uji bahan ajar kepada siswa sebagai subjeknya. Subjek yang digunakan yaitu siswa kelas X Mipa SMA 1 Pelaihari sebanyak 15 siswa.

Rancangan uji efektivitas menggunakan penilaian pre tes pos tes. Data hasi tes siswa sebelum dan sesudah diberikan perlakuan kemudian dianalisis dengan cara membandingkan skornya menggunakan rumus faktor $\mathrm{g}(\mathrm{N}$-gain) yang dikembangkan oleh Hake (1999).

Peningkatan hasil belajar siswa dapat dihitung menggunakan rumus gain sebagai berikut:

Keterangan:

$$
\mathrm{g}=\frac{S \text { postest }-S \text { pretest }}{S \text { maksimum }-S \text { pretest }}
$$

$\begin{array}{ll}\mathrm{g} & : \text { Nilai gain } \\ \mathrm{S} \text { postest } & : \text { skor postes } \\ \mathrm{S} \text { pretest } & : \text { skor pretes }\end{array}$

Adapun Tabel 1 terkait klasifikasi $\mathrm{N}$-gain sebagai berikut:

Tabel.1 klasifikasi N-gain

\begin{tabular}{ll}
\hline Nilai $\mathbf{g}$ & Kategori \\
$\mathrm{G} \geq 0,7$ & Tinggi \\
$0,7>\mathrm{g} \geq 0,3$ & Sedang \\
$\mathrm{G}<0,3$ & Rendah \\
\hline
\end{tabular}

\section{HASIL PENELITIAN DAN PEMBAHASAN}

Hasil pengembangan bahan ajar yang dilakukan yaitu pengembangan bahan ajar berbasis potensi lokal, adapun buku yang dihasilkan ada pada gambar. 1. Ketika uji efektivitas dilaksanakan, siswa diberikan masing-masing buku ajar dan menggunakannya secara mandiri. Kemudian siswa diarahkan untuk menuju sungai terdekat dari lingkungan sekolahan untuk melakukan praktek secara langsung, yaitu menangkap jenis-jenis ikan yang ditemukan kemudian mengidentifikasi jenis-jenis ikan berdasarkan ciri-ciri yang ada pada buku ajar tersebut.

Buku ajar tersebut memuat 3 bab yang terdiri atas pendahuluan, isi dan penutup. Pada bagian bab I pendahuluan, memaparkan bentuk-bentuk morfologi hingga ciri-ciri ikan berdasarkan bentuk-bentuknya, bab II jenis-jenis ikan yang ditemukan di sungai Panjaratan, Pelaihari, bab III evaluasi terdiri dari LKS, kuis, glosarium, dan simpulan. 

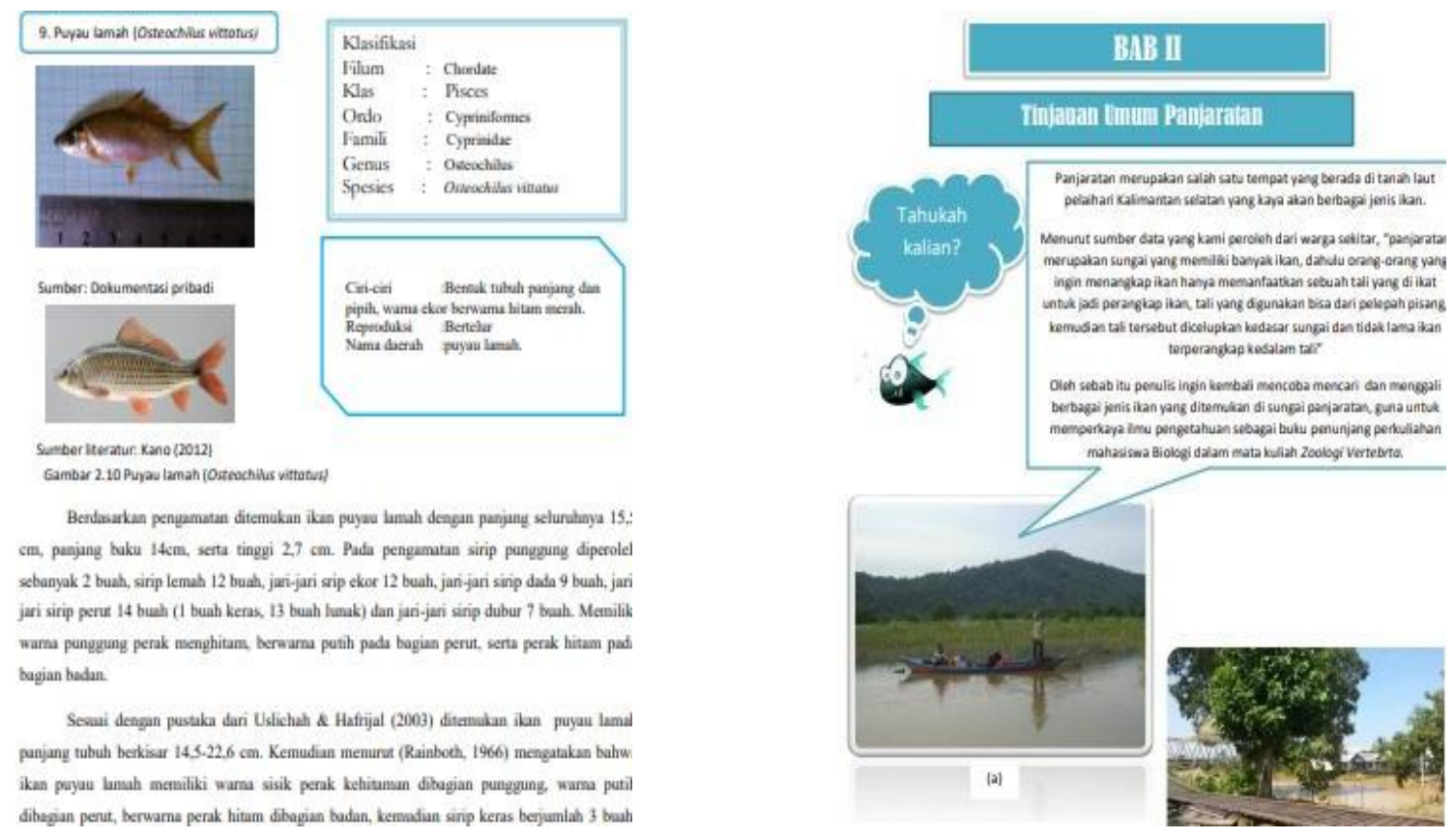

Gambar 1. Bahan ajar berbasis potensi lokal yang dikembangkan

Setelah serangkaian uji maka dilanjutkan mengukur efektivitas dari bahan ajar. Adapun hasil belajar siswa terlihat pada tabel 2 .

Tabel 2. Hasil Belajar Siswa pada Uji Lapangan

\begin{tabular}{|c|c|c|c|c|c|c|}
\hline \multirow{2}{*}{ No. } & \multirow{2}{*}{$\begin{array}{l}\text { Nama } \\
\text { Siswa }\end{array}$} & \multicolumn{2}{|c|}{ Skor } & \multirow{2}{*}{$\begin{array}{c}\text { Standar Nilai } \\
(\mathrm{KKM})\end{array}$} & \multirow[b]{2}{*}{ g } & \multirow{2}{*}{$\mathrm{N}$-gain } \\
\hline & & Pre Test & Post Test & & & \\
\hline 1. & MF & 60 & 90 & Tuntas & 0,75 & Tinggi \\
\hline 2. & ABA & 40 & 85 & Tuntas & 0,75 & Tinggi \\
\hline 3. & $\mathrm{WH}$ & 30 & 80 & Tuntas & 0,71 & Tinggi \\
\hline 4. & BS & 50 & 80 & Tuntas & 0,60 & sedang \\
\hline 5. & DR & 60 & 95 & Tuntas & 0,88 & Tinggi \\
\hline 6. & PDE & 40 & 85 & Tuntas & 0,75 & Tinggi \\
\hline 7. & GS & 60 & 90 & Tuntas & 0,75 & Tinggi \\
\hline 8. & B & 40 & 80 & Tuntas & 0,67 & sedang \\
\hline 9. & DA & 60 & 90 & Tuntas & 0,75 & Tinggi \\
\hline 10. & VN & 60 & 95 & Tuntas & 0,88 & Tinggi \\
\hline 11. & FR & 30 & 85 & Tuntas & 0,79 & Tinggi \\
\hline 12. & BA & 30 & 80 & Tuntas & 0,71 & Tinggi \\
\hline 13. & MR & 70 & 95 & Tuntas & 0,83 & Tinggi \\
\hline 14. & $\mathrm{AH}$ & 40 & 80 & Tuntas & 0,67 & sedang \\
\hline 15. & HW & 50 & 90 & Tuntas & 0,80 & Tinggi \\
\hline & Jumlah & & & 15 & & \\
\hline & Rata-rata & 48 & 80,67 & & 0,75 & Tinggi \\
\hline
\end{tabular}

Keterangan : Nilai $\mathrm{KKM}=75$

Menurut (Krisna Anggraeni \& Devi Afriyuni Yonanda, 2018) nilai efektivitas dapat ditunjukkan dari peningkatan nilai pretes dan postes. Berdasarkan hasil belajar siswa pada uji kelompok kecil setelah dilakukan pembelajaran, menunjukkan bahwa terjadi peningkatan hasil belajar yang signifikan dengan rata-rata nilai 48 pada Pre Test dan 80,67 pada Post Test. Semua siswa tuntas walaupun tidak ada siswa yang mencapai nilai 100. Berdasarkan perhitungan nilai gain didapatkan rata-rata nilai 0,75 dengan

76 Meyninda Destiara - Efektivitas Bahan Ajar Berbasis Potensi Lokal Pada Materi Pisces Terhadap Hasil Belajar 
kategori $\mathrm{N}$-gain tinggi, ini menunjukkan peningkatan pemahaman atau penguasaan konsep siswa setelah pembelajaran dilakukan adalah tinggi. Serupa dengan penelitian oleh (Sari et al., 2018) peningkatan N-gain siswa terlihat setelah diterapkan bahan ajar dan menambah kemampuan berpikir kritis pada siswa.

Peningkatan tersebut tidak jauh merupakan peran dari sebuah buku ajar yang dapat menambah motivasi dan semangat siswa dalam belajar (Sujarwo, 2014), serta dengan memanfaatkan potensi lokal sebagai fasilitas belajar dapat memancing rasa ingin tahu siswa lebih dalam (Situmorang, 2016). Hal ini sesuai menurut (Asri, 2012) bahwa pemanfaatan potensi lokal sebagai sumber belajar akan berdampak pada kesadaran dalam mengelola alam dan menunjukkan keterampilan Problem solving dakam memecahkan berbagai masalah yang ada di alam. Sehingga terlihat pada efektivitas hasil belajar siswa meningkat setelah diberikan perlakukan penggunaan bahan ajar dari potensi lokal.

\section{SIMPULAN DAN SARAN}

Berdasarkan penelitian tersebut, maka didapatkan kesimpulan bahwa bahan ajar berbasis potensi lokal pada konsep vertebrata efektif, dilihat dari peningkatan nilai gain atau $\mathrm{N}$-gain yang menunjukkan rata-rata 0,75 dengan katagori tinggi.

\section{RUJUKAN}

Arikunto, S. (2010). Prosedur Penelitian Suatu Pendekatan Praktek. Jakarta; Rineka Cipta.

Anisa, A. (2017). Meningkatkan keterampilan berpikir kritis peserta didik melalui pembelajaran IPA berbasis potensi lokal Jepara. Jurnal Inovasi Pendidikan IPA, 3(1), 1. https://doi.org/10.21831/jipi.v3i1.8607

Asri, W. (2012). Optimalisasi Potensi Lokal Sekolah Dalam Pembelajaran Biologi Berbasis Kontruktivisme. Majalah Ilmiah Pembelajaran, 8(2).

Depdiknas. (2007). Permendiknas No 41 Tahun 2007, Standar Proses. Jakarta: Depatemen Pendidikan Nasional.

Depdiknas. (2008). Panduan Pengembangan Bahan Ajar. Jakarta: Departemen Pendidikan Nasional.

Destiara, M., Soendjoto, M. A., Biologi, M. P., Mangkurat, U. L., Selatan, K., Kehutanan, F., Mangkurat, U. L., \& Selatan, K. (2018). Validitas Bahan Ajar Jenis Ikan di Sungai Panjaratan Pada Konsep Vertebrata SMA Kelas X. 9(1), 31-37.

Krisna Anggraeni, \& Devi Afriyuni Yonanda. (2018). Efektivitas Bahan Ajar Berbasis Kearifan Lokal Dalam Model Pembelajaran Teknik Jigsaw Terhadap Keterampilan Menulis Deskripsi. Visipena Journal, 9(2), 385-395. https://doi.org/10.46244/visipena.v9i2.467

Mardotilah, F. (2016). Efektivitas Pembelajaran Fisika Menggunakan Lembar Kerja Siswa ( Lks ) Fisika Berbasis Kearifan. Jipf, 116-124.

Nurhidayati, S., \& Khaeruman, K. (2017). Pengembangan Bahan Ajar Bioteknologi Berbasis Potensi Lokal. Jurnal Pendidikan Mandala, 2(2), 87-91.

Prabowo, D. L., Nurmiyati, \& Maridi. (2016). Pengembangan modul berbasis potensi lokal pada materi ekosistem sebagai bahan ajar di SMAN 1 Tanjungsari, Gunungkidul. Proceeding Biology Education Conference, 13(1), 192- 
195. https://media.neliti.com/media/publications/174711-ID-pengembanganmodul-berbasis-potensi-loka.pdf

Sari, R., Harijanto, A., \& Wahyuni, S. (2018). Pengembangan Lks Ipa Berbasis Kearifan Lokal Kopi Pada Pokok Bahasan Usaha Dan Energi Di Smp. Jurnal Pembelajaran Fisika, 7(1), 70. https://doi.org/10.19184/jpf.v7i1.7227

Situmorang, R. (2016). Analisis Potensi Lokal Untuk Mengembangkan Bahan Ajar Biologi Di Sma Negeri 2 Wonosari. Jurnal Pendidikan Sains Universitas Muhammadiyah Semarang, 4(1), 51-57.

https://doi.org/10.26714/jps.4.1.2016.51-57

Soegiranto, R.E. (2010). Acuan Penulisan Bahan Ajar dalam Bentuk Modul. Pokja Kurikulum dan Sprevisi Pusat Pengembangan Madrasah Kementrian Agama Provinsi Nusa Tenggara Timur

Sujarwo. (2014). Pengembangan Bahan Ajar Berbasis Potensi Lokal pada Program Pendidikan Keaksaraan Usaha Mandiri. Jurnal AKRAB, V(1), 26-35.

Utomo, A. P. (2016). Pembelajaran Pengetahuan Lingkungan the Learning of Environmental Science Using. Jurnal Biologi Dan Pembelajaran Biologi, 1(1), 1428. 